EXTENDED REPORT

\title{
Ahmed valve drainage implant surgery in the management of paediatric aphakic glaucoma
}

\author{
C Kirwan, M O'Keefe, B Lanigan, U Mahmood
}

Br J Ophthalmol 2005;89:855-858. doi: 10.1136/bjo.2004.056143

See end of article for authors' affiliations

.....................

Correspondence to: Professor Michael O'Keefe, The Children's University Hospital, Temple Street, Dublin 1, Republic of Ireland; mokeefe@ materprivate.ie

Accepted for publication 2 December 2004

\begin{abstract}
Background: Paediatric aphakic glaucoma presents months or years after cataract surgery in children and is a major long term complication. The results of surgical treatment are poor and many children require multiple and repeat procedures with poor visual outcomes.

Methods: 13 children (19 eyes) had Ahmed valve implantation surgery, nine of the children had previous procedures such as cycloablation or trabeculectomy. Mitomycin was used at surgery in some patients and valve needling with Healon GV and 5-fluorouracil in some blebs after surgery. $\mathrm{SF}_{6}$ gas was also used at the time of surgery in most children to reform the anterior chamber.

Results: 12 of the children (18 eyes) achieved intraocular pressure control of $15 \mathrm{~mm} \mathrm{Hg}$ or less with a valve alone or with additional medical therapy.

Conclusion: Ahmed valve implantation surgery alone or in combination with medical therapy is successful and safe in the management of paediatric aphakic glaucoma.
\end{abstract}

A phakic glaucoma is a major long term complication following congenital cataract surgery. ${ }^{1-3}$ It presents months or years after surgery and is associated with younger age at surgery. ${ }^{4}$ Micro cornea and secondary membrane surgery may also play a part.

The reported frequency has ranged from $1-35 \% .^{56}$ The variation among studies relates to difference in duration of follow up, and inclusion or exclusion of other ocular abnormalities.

The aim of this study is to record the success, complications, and visual outcome using Ahmed valve implants, and the longer term follow up.

\section{PATIENTS AND METHODS}

We conducted a retrospective chart review of all patients who underwent Ahmed valve surgery for paediatric aphakic glaucoma between 1996 and 2003. All the patients included in this study attend for regular follow up visits in our clinic. Diagnosis of glaucoma was mainly based on changes in the optic discs and intraocular pressure. All of the surgeries were preformed by one surgeon $\left(\mathrm{MO}^{\prime} \mathrm{K}\right)$. Indications for valve insertion included intraocular pressure not controlled by medical therapy or other forms of surgery-namely, cycloablation and or trabeculectomy. The Ahmed valve used was model S2 from New World Medical (Rancho Cucamonga, CA, USA).

Surgical technique involved a fornix based conjunctival flap in the superior temporal or nasal quadrant. The sclera was exposed. In 10 eyes $0.5 \mathrm{mg} / \mathrm{ml}$ mitomycin $C$ was applied to the sclera for 3 minutes and onto the valve itself. The tube was primed using balanced salt solution. The plate was secured to the sclera with its anterior edge $6 \mathrm{~mm}$ posterior to the limbus using 7.0 Prolene sutures. A sclera tunnel was created starting approximately $2 \mathrm{~mm}$ from the limbus and, using a 23 gauge or 25 gauge needle the tunnel was advanced into the anterior chamber of the eye. The tube was trimmed bevel up and inserted through the tunnel into the anterior chamber aiming towards the centre of the pupil. The tube was not ligated. A donor scleral patch was placed over the sclera tunnel to cover the tube. This was sutured to the sclera with $9 / 0$ nylon sutures. The conjunctiva was reapposed using 6/0 Vicryl sutures. In most patients, a volume of $0.5 \mathrm{ml}$ of $20 \% \mathrm{SF}_{6}$ (sulphur hexafluoride gas) was injected into the anterior chamber through a long corneal tunnel to maintain anterior chamber depth and prevent hypotony. Maxitrol ointment was applied to the eye and the eye was double padded for 24 hours.

\section{RESULTS}

There were 13 patients (seven males, six females) and a total of 19 eyes in the study. Nine eyes had surgical procedures carried out before valve insertion, three had cycloblation alone, one had trabeculectomy alone, and five had both. The follow up period was between 1996 and 2003 with three patients having a follow up of more than 6 years (table 1 ). There was a mean reduction in intraocular pressure of $18 \mathrm{~mm} \mathrm{Hg}$ (range $8-26 \mathrm{~mm} \mathrm{Hg}$ ). We choose a target postoperative intraocular pressure of $15 \mathrm{~mm} \mathrm{Hg}$ as the goal in all patients. To attain this some patients required additional medical treatment in addition to the valve. This was either a single medication such as betaxolol or latanoprost or a combination of these and dorzolamide or timolol (table 2). Complete success was achieved in six eyes from four patients with valve alone with an additional 12 eyes from eight patients requiring additional medical treatment in order to

\begin{tabular}{|ll|}
\hline Table 1 Patient demographics & \\
\hline Number of patients & 13 \\
Male:female & $7: 6$ \\
Number of eyes & 19 \\
Age at insertion of Ahmed valve (months) & 96 \\
$\quad$ Mean & $9-189$ \\
$\quad$ Range & 17.9 \\
Reduction in IOP (mm Hg) & $8-26$ \\
$\quad$ Mean & 9 \\
$\quad$ Range & 1 \\
Previous surgical procedures & 3 \\
Trabeculectomy alone & 5 \\
$\quad$ Cycloablation alone & 32 \\
Trabeculectomy + cycloablation & $3-84$ \\
Length of follow up (months) & \\
$\quad$ Mean & \\
Range & \\
\hline
\end{tabular}


Table 2 Time of surgery, age at surgery, intraocular pressure (IOP) measurements, pre-Ahmed valve insertion, 3 months and 6 months postoperatively, and pressure drop calculated from preoperative to latest postoperative recording

\begin{tabular}{|c|c|c|c|c|c|c|c|}
\hline Patient & Date of surgery & $\begin{array}{l}\text { Age at surgery } \\
\text { (months) }\end{array}$ & $\begin{array}{l}\text { Preop IOP } \\
(\mathrm{mm} \mathrm{Hg})\end{array}$ & $\begin{array}{l}\text { IOP } 3 \text { months } \\
\text { postop }(\mathrm{mm} \mathrm{Hg})\end{array}$ & $\begin{array}{l}\text { IOP } 6 \text { months } \\
\text { postop }(\mathrm{mm} \mathrm{Hg})\end{array}$ & $\begin{array}{l}\text { Latest IOP } \\
\text { (months postop) }\end{array}$ & $\begin{array}{l}\text { Pressure drop } \\
\text { (pre-latest postop) }\end{array}$ \\
\hline DP & 14 Mar 01 - & 17 & $34^{*}$ & 21 & $24^{*}$ & $15^{\star}$ (35 months) & 19 \\
\hline SP & 15 Jan $03+\#$ & 154 & $28^{*}$ & 12 & $15^{*}$ & $15^{*}$ (13 months) & 13 \\
\hline $\mathrm{AMC}$ & 20 Jul 01 + & 18 & $28^{*}$ & 14 & $6^{*}$ & 8 (31 months) & 20 \\
\hline \multirow[t]{2}{*}{ EG } & 28 May 97 - \# & 9 & $34^{*}$ & 4 & 5 & 12 (84 months) & 22 \\
\hline & $5 \mathrm{Nov} 03+$ & 87 & $32^{*}$ & 12 & 12 & 12 (6 months) & 20 \\
\hline \multirow[t]{2}{*}{ CG } & 11 Oct $02+\#$ & 125 & $26^{*}$ & $19^{*}$ & $16^{*}$ & $18^{*}$ (45 months) & 8 \\
\hline & 27 Mar $02+\#$ & 142 & $40^{*}$ & $23^{*}$ & $14^{*}$ & $18^{*}$ (28 months) & 22 \\
\hline \multirow[t]{2}{*}{ SK } & 8 Apr 98 - \# & 114 & $30^{*}$ & $12^{*}$ & $16^{*}$ & $16^{*}$ (71 months) & 14 \\
\hline & 3 Nov 99 - \# & 157 & $40^{*}$ & 8 & 10 & $14^{*}$ (52 months) & 20 \\
\hline \multirow[t]{2}{*}{$\mathrm{HN}$} & 26 Jun $02+\#$ & 188 & $28^{*}$ & $14^{*}$ & $14^{*}$ & $14^{*}$ (21 months) & 14 \\
\hline & 24 Jul 02 - \# & 189 & $34^{*}$ & $14^{*}$ & $14^{*}$ & $12^{*}(20$ months $)$ & 22 \\
\hline LK & 17 Jun 98 - \# & 92 & $36^{*}$ & 10 & 11 & 10 (70 months) & 26 \\
\hline \multirow[t]{2}{*}{ HM } & 27 Feb $02-$ & 104 & $29^{*}$ & $16^{*}$ & $15^{*}$ & $13^{*}$ (28 months) & 16 \\
\hline & 18 Jun $03+$ & 120 & $26^{*}$ & $14^{*}$ & $16^{*}$ & $14^{*}$ (12 months) & 12 \\
\hline \multirow[t]{2}{*}{ SF } & 17 Sep $03+$ & 34 & $28^{*}$ & $6^{*}$ & NA & $6^{*}$ (3 months) & 22 \\
\hline & 8 Oct $03+$ & 35 & $31^{*}$ & $7^{*}$ & NA & $7^{*}$ (4 months) & 24 \\
\hline GD & 7 Mar 01 - & 28 & $28^{*}$ & $18^{*}$ & valve removed & NA & NA \\
\hline CG & 11 Aug 99 - & 85 & $30^{*}$ & $12^{*}$ & $20^{*}$ & $16^{*}$ (52 months) & 14 \\
\hline$C D$ & 7 Mar $01-$ & 130 & $28^{*}$ & $16^{*}$ & $17^{*}$ & $14^{*}$ (15 months) & 14 \\
\hline
\end{tabular}

achieve desired control. Only one eye was considered a failure. Mitomycin was used at surgery in 10 eyes. There was no postoperative difference in intraocular pressure measurement or complications in patients with or without mitomycin. Repeat needling of the valve using a 23 gauge needle, Healon GV, and 5-fluorouracil was carried out in 12 eyes in the first 6 months when the intraocular pressure increased. Healon GV was injected under the conjunctival bleb over the valve plate to free any adhesions. Fluorouracil, $5 \mathrm{mg} / 0.2 \mathrm{ml}$, was then injected into the Healon over the plate to create longer term inhibition of fibroproliferative activity. In three eyes the procedure was repeated 3 years or more after surgery. We noted a successful outcome from needling if there was an immediate drop in intraocular pressure. The visual outcome varied but was poor and seven of the eyes have visions of $6 / 60$ or less. There was no loss of vision from this surgery (table 3 ).

Complications occurred in five patients (table 4). They included hypotony and choroidal detachment in two eyes of two patients. There was corneal touch in two eyes of two patients. The valve was removed in two further patients one for persistent ocular pain in a second eye. However, 3 months later a valve was re-inserted because of the recurrence of glaucoma and no further pain was experienced. The patient continues to have a successful outcome. The other, a child

\begin{tabular}{lll} 
Table 3 & Visual outcome & \\
\hline & \multicolumn{2}{c}{ Visual acuity } \\
\cline { 2 - 3 } Patient & Right eye & Left eye \\
\hline DP & $6 / 24^{*}$ & $6 / 24$ \\
SP & $6 / 36$ & $2 / 60^{*}$ \\
AMC & $6 / 24^{*}$ & $6 / 24$ \\
EG & $6 / 24^{*}$ & $6 / 24^{*}$ \\
CG & $6 / 36^{*}$ & $6 M^{*}$ \\
SK & $6 / 60^{*}$ & $6 / 24^{*}$ \\
HN & $6 / 36^{*}$ & $6 / 12^{*}$ \\
LK & $6 / 6$ & $C F^{*}$ \\
HM & $3 / 60^{*}$ & $6 / 18^{*}$ \\
SF & $6 / 9^{*}$ & $6 / 9^{*}$ \\
GD & $6 / 60^{*}$ & $6 / 60$ \\
CD & $6 / 60$ & $6 / 9^{*}$ \\
CG & $C F^{*}$ & $6 / 12$ \\
\hline
\end{tabular}

$\mathrm{HM}$, hand movement visual acuity; $\mathrm{CF}$, counting finger visual acuity. ${ }^{*}$ Ahmed valve in situ. with Lowe's syndrome dislocated a tube because of persistent aggressive rubbing of the eye and we chose not to reinsert it. This child has uncontrolled pressure on medical therapy and has a superficial corneal scar secondary to rubbing.

\section{DISCUSSION}

The high failure rate of trabeculectomy with or without antimetabolites in children with aphakic glaucoma has led to a search for an alternative. ${ }^{7}$ The additional use of antimetabolite increases the longer term side effects. ${ }^{8}$ The use of medical therapy is in most cases only an adjunctive treatment and ciliary body ablative procedures such as cyclodiode laser may only have a short term benefit. ${ }^{9}$ The poor success rate and potential complications with many of the surgical procedures may result in a delay in treatment until the glaucoma is much more advanced before intervention occurs.

In 1968 Molteno introduced the first drainage implant to treat refractory glaucoma. ${ }^{10}$ Over the past few decades, nonvalved implants such as Molteno, Baerveldt, and Schocket and valved implants such as Krupin, Ahmed, and Opti-Med, have been used in children. The Ahmed valve was first used in 1993. The aqueous flow is directed to the posterior plate and aqueous is absorbed by orbital capillaries and lymphatics. ${ }^{11}$ We chose the Ahmed valve because of its reduced tendency for overfiltration. It is implanted in a single stage procedure and the intraocular pressure is reduced in the immediate postoperative period.

The use of glaucoma drainage implant devices has improved the outcome in neovascular glaucoma and in glaucoma following uveitis, aphakia, and post-penetrating keratoplasty. ${ }^{10}{ }^{11}$ To achieve this many of the eyes require additional medical therapy either with one or more medications. More recently the safety and efficacy of surgery using drainage implants compared with trabeculectomy for initial surgical management of primary open angle glaucoma has

\begin{tabular}{ll} 
Table 4 Complications & \\
\hline Complication & Number of eyes \\
\hline Choroidal detachment/hypotony & 2 \\
Corneal touch & 2 \\
Valve removal & 2 \\
\hline
\end{tabular}


been demonstrated..$^{12-14}$ The reduction in intraocular pressure and frequency of complications was comparable between the two groups. If one takes an intraocular pressure below $21 \mathrm{~mm} \mathrm{Hg}$, then the success in the literature ranges from about $45 \%$ to $90 \%$. Coleman et al ${ }^{15}$ reported an overall success rate of $78 \%$ and $61 \%$. Englert reported a success rate of $91 \%$ and $58 \%$ during a 1 year and 2 year follow up ${ }^{16}$ Djodeyre et $a l^{17}$ reported an overall success rate of $70 \%$ and $63 \%$ at 12 months and 24 months respectively. More recently Morad et al highlighted a decreased success rate of $71 \%$ and $46 \%$ after 36 and 48 months after surgery. ${ }^{18}$ Donahoe et al showed a greater success rate with drainage implants for aphakic glaucoma in those who had only one previous surgery. ${ }^{19}$ The other surgical techniques such as trabeculectomy with mitomycin are 59\% and $67 \%$ at 12 and 24 months and cycloablation $66 \%$ and $44 \%$ at 6 months and 57 months. ${ }^{20} 21$ In a comparison of aqueous shunt devices versus trabeculectomy with mitomycin for children under 2 years of age, aqueous shunt devices offered a better chance of successful glaucoma control in the first 2 years of life..$^{22}$

Our results compare favourably with these other studies. What is more important is we have set a lower intraocular pressure as our goal. To achieve this many of the eyes require additional medical therapy either with one or more than one medication. The mean reduction in intraocular pressure of $18 \mathrm{~mm} \mathrm{Hg}$ is similar to others..$^{15}$ A very important observation is that the intraocular pressure remains well controlled in three eyes with more than 6 years of follow up. The success rate is not poorer in patients who have had multiple surgeries, such as cycloblation or trabeculectomy, as illustrated in nine of our patients. The success of needle revision of failed and failing trabeculectomy blebs with adjunctive 5 -fluorouracil has been recently highlighted. ${ }^{23}$ We have found a similar technique useful in our patients where there is a reduction in the control of intraocular pressure. We have used this technique 3 years or more after the initial surgery with successful outcome. A useful indicator of successful response is the finding of a drop in intraocular pressure immediately after the needling of the valve with 23 gauge needle, Healon GV and the injection of 5-fluorouracil into the Healon. This technique was first demonstrated to the authors by Peng Khaw (personal communication).

Most of the needlings were performed in the first 6 months after valve insertion, when the rise in intraocular pressure occurred. The initial hypertensive phase was reported by Ayyala et $a l^{24}$ and Kooris et al. ${ }^{25}$ Histological examination described the emergence of a dense layer of fibrous tissue over the plate with a consequent rise in intraocular pressure.

The hypertensive phase may be transient in some patients. It is also claimed that its presence early in the postoperative period may be associated with an unfavourable outcome and most of these eyes may need continuing medical therapy. ${ }^{25}$ The hypertensive phase is thought to be more frequent with the Ahmed valve because of its reduced surface area. The fact that needling and 5-fluorouracil have a beneficial effect points to congestion, oedema, inflammation, and early fibrosis as the cause.

Mitomycin is now established as an essential agent for trabeculectomies in most forms of refractory glaucoma and in other high risk patients. ${ }^{26}$ It carries potential side effects both long and short term, such as bleb leakage and infection. Our rationale in using it in some patients is to reduce Tenon cyst and bleb encapsulation over the valve. We found no difference in intraocular pressure control or complications using this agent; it is worth stating that this was not randomised and there were 13 patients. The valve was used in other types of glaucoma with mitomycin without increased complication rate. In the largest single trial on children with Ahmed valve drainage implants complications occurred in
$50 \%$ (30 of 60 eyes). ${ }^{16}$ Hypotony with choroidal effusion was the commonest complication in $23 \%$. Other complications such as tube exposure, endophthalmitis, and ocular motility problems were also noted. Postoperative hypotony is a major problem with all valve implants but is less common with the Ahmed valve because of the unidirectional flow. The special valve mechanism is designed to prevent complications of overfiltration in the immediate postoperative period. However, we have encountered hypotony in two eyes with choroidal detachment and one required anterior chamber reformation. We have used $\mathrm{SF}_{6}$ gas for some patients at the time of surgery and it is our view that this reduces the risk of hypotony. It remains in the eye for 72 hours, giving enough time for aqueous production and the increase of intraocular pressure to a level sufficient to prevent hypotony. Two of our earlier patients had corneal touch, which is an avoidable surgical risk and is eliminated with improved surgical technique. Our more severe complication was valve displacement caused by excess rubbing, which resulted in valve failure. It is worth highlighting this as we think that this type of valve surgery may be contraindicated in some children. Visual outcome in many of our patients is poor, with most children achieving 6/24 best visual acuity and seven eyes achieving vision of $6 / 60$ or less. This is not the result of valve surgery itself. These children have amblyopia.

Aphakic glaucoma is usually asymptomatic and to detect this disease adequately many require regular examinations under anaesthesia. A further dilemma is in deciding one's criteria for diagnosing glaucoma; in particular, does one make the diagnosis on intraocular pressure alone or optic disc changes. Treatment, particularly surgery, is difficult and tedious and understandably there is sometimes a delay in performing surgery.

The complications and longer term failure of valve implants have been major obstacles to their insertion in children. There is an initial learning curve. The intraocular pressure result is impressive and is lasting at least 5 years or more in patients with longer term follow up. We confirm the success of valve needling as a useful and safe technique, both early on after surgery and in the longer term. We also recommend the use of $\mathrm{SF}_{6}$ gas at initial surgery to reduce hypotony and choroidal detachment as it is safe, effective, and easy to administer. The complications in this series were low. This in our view is a major positive feature of the Ahmed valve. The newer Bl double plated Ahmed valves with total plate surface area of $364 \mathrm{~mm}^{2}$, one valve plate body, and a non-valve plate may be more effective in lowering the intraocular pressure and reducing further the need for adjunctive medical therapy. ${ }^{27}$

Finally, we acknowledge that this study is retrospective, with a small number of patients and there is the need for longer term follow up. To date, valves have been reserved for treatment of refractory glaucoma. We believe that there is now a good case for them to be considered as first choice in surgical management of paediatric aphakic glaucoma.

\section{Authors' affiliations \\ C Kirwan, M O'Keefe, B Lanigan, U Mahmood, The Children's University Hospital, National Children's Eye Centre, Temple Street, Dublin, and University College Dublin, Republic of Ireland}

\section{REFERENCES}

1 Phelps CD, Arafat NI. Open angle glaucoma following surgery for congenital cataracts. Arch Ophthalmol 1977;95:1985-7.

2 Mills MD, Robb RM. Glaucoma following childhood cataract surgery. J Pediatr Ophthalmol Strabismus 1994;31:355-60.

3 Russell Eggitt I, Zamiri P. Review of aphakic glaucoma after surgery for congenital cataract. J Cataract Refract Surg 1997;23:664-8.

4 Vishwarath $M$, Cheong Leen $R$, Taylor $D$, et al. Is early surgery for congenital cataracts a risk for glaucoma? Br J Ophthalmol 2004;88:905-10. 
5 Rabiah P. Frequency and predictors of glaucoma after pediatric cataract surgery. Am J Ophthalmol 2004;137:30-7.

6 Simon JD, Mehta N, Simmons ST, et al. Glaucoma after pediatric lensectomy/ vitrectomy. Ophthalmology 1991:98:670-4.

7 Mandal AK, Bagga $H$, Nutteti $R$, et al. Trabeculectomy with or without mitomycin $C$ for pediatric glaucoma in aphakia and pseudophakia following congenital cataract surgery. Eye 2003;17:53-62.

8 Wells AP, Cordeiro F, Bunie C, et al. Cystic bleb formation and related complications in limbic versus formix based conjunctival flaps in paediatric and young adult trabeculectomy with mitomycin C. Ophthalmology 2003;110:2192-7.

9 Phelan MJ, Higginbottam EJ. Contact transcleral Nd:Yag laser cyclophoria coagulation for refractory paediatric glaucoma. Ophthalmic Surg Lasers 1995;26:401-3

10 Molteno ACB. New implant for drainage in glaucoma: clinical trial. Br J Ophthalmol 1979;53:606-15.

11 Rosenberg LF, Krupin T. Implants in glaucoma surgery. In: Peter R, Shields MB Krupin T, eds. The glaucomas. 2nd ed. Philadelphia: Mosby 1996:1783-807.

12 Hever DK, Lloyd MA, Abrams DA. Which is better? A randomized clinical trial of single plate versus double plate Molteno implantation for glaucoma in aphakia and pseudophakia. Ophthalmology 1992;99:1512-19.

13 Mills RP, Reynolds A, Edmond MJ. Long term survival of Molteno glaucoma drainage devices. Ophthalmology 1996;103:299-305.

14 Wilson R, Mendis IL, Smith SD, et al. Ahmed glaucoma valve implant vs trabeculectomy in the surgical treatment of glaucoma a randomized clinical trial. Am J Ophthalmol 2000;130:267-73.

15 Coleman AL, Smyth RJ, Wilson MR, et al. Initial clinical experience with the Ahmed glaucoma valve implant in pediatric patients. Arch Ophthalmol 1997; 115:186-91.
16 Englert JA, Freedman SF, Cox TA. The Ahmed valve in refractory pediatric glaucoma. Am J Ophthalmol 1999;127:34-42.

17 Diodeyre MR, Calvo JP, Gomez JA. Clinical evaluation and risk factors of time to failure of Ahmed glaucoma valve implant in pediatric patients. Ophthalmology 2001;108:614-20.

18 Morad Y, Donaldson C, Fraco F, et al. The Ahmed drainage implant in the treatment of pediatric glaucoma. Am J Ophthalmol 2003;135:821-9.

19 Donahoe SP, Keech RV, Munden P, et al. Baerveldt implant surgery in the treatment of advanced childhood glaucoma. J AAPOS 1997;1:41-5.

20 Beck AD, Wilson WR, Lynch MG. Trabeculectomy with adjunctive mitomycin $\mathrm{C}$ in pediatric glaucoma. Am J Ophthalmol 1998;126:648-57.

21 Freedman SF, McCormick K, Cox TA. Mitomycin C-augmented trabeculectomy with postoperative modulation in pediatric glaucoma. $J$ AAPOS 1999:3:117-24.

22 Beck AD, Freedman S, Kammer J, et al. Queous shunt devices compared with trabeculectomy with mitomycin-C for children in the first two years of life. Am J Ophthalmol 2003;136:994-1000

23 Broadway D, Bloom P, Bunee C, et al. Needle revision of failing and failed trabeculectomy blebs with adjunctive 5 fluorouracil. Ophthalmology 2004;111:665-73.

24 Ayyala RS, Zurakowski D, Smith JA, et al. A clinical study of the Ahmed glaucoma valve implant in advanced glaucoma. Ophthalmology 1998; 105:1968-76

25 Kouros Nouri-Mahdavi, Caprioli J. Evaluation of the hypertensive phase after insertion of the Ahmed glaucoma valve. Am J Ophthalmol 2003;136:1001-8.

26 Katz GI, Higginbottam EJ, Lihter PR. Mitomycin C vs 5-fluorouracil in high risk glaucoma filtering surgery. Extended follow up. Ophthalmology 1995; 102:1263-9.

27 Miele DL, Herndon L, Leep. Early clinical experience with Ahmed glaucoma bilateral plate. ARVO 2002:6. 